\title{
Difficult Airway in Diabetes
}

\author{
Leonard Nowcid, MD; Elizabeth Valentine, MD
}

Department of Anesthesiology and Critical Care ; Perelman School of Medicine at the University of Pennsylvania

The incidence of diabetes continues to grow both in the United States and internationally. It is estimated by the International Diabetes Federation that 382 million people worldwide are currently diagnosed with the disease and that the prevalence will nearly double by 2030. ${ }^{1,2}$ Based on these statistics, diabetes is one of the most common endocrine disorders that the anesthesiologist will encounter in practice.

Airway management is of paramount concern in every anesthetic. The American Society of Anesthesiologists (ASA) has defined a difficult airway as, "the clinical situation in which a conventionally trained anesthesiologist experiences difficulty with facemask ventilation of the upper airway, difficulty with tracheal intubation, or both." 3 In 2013, the ASA updated the practice guidelines from 2003 for the management of the difficult airway. It has been estimated that the incidence of difficult airways in the general population may be as high as $4.5-7.5 \%{ }^{4}$

It has been previously suggested that diabetic patients may be at higher risk for a difficult airway than the general population. In this mini review, we will discuss the potential for difficult laryngoscopy in this patient population since many of these patients will require surgical interventions due to complications of their medical pathophysiology.

\section{Should the Anesthesiologist Anticipate a Difficult Airway in a Patient with Type 1 Diabetes?}

Type 1 diabetics make up only a small portion of the total number affected by the disease, but it is one of the most common chronic diseases of childhood. ${ }^{5}$ In the United States, the incidence of type 1 diabetics in non-Hispanic white children and adolescents is 23.6 per 100,000 people per year and varies based upon geography, age, gender, family history, and ethnicity. ${ }^{6}$

In a 1988 paper from Anesthesia and Analgesia, Hogan et al. described an increase incidence of difficult laryngoscopies in type 1 diabetic patients undergoing renal transplants when compared to non-diabetic patients ( $32 \%$ vs $2.7 \%)^{7}{ }^{7}$ They defined difficult laryngoscopy as an airway in which an attending anesthesiologist was unable to directly visualize any part of the vocal cords using conventional direct laryngoscopy. In the majority of cases the endotracheal tube was passed blindly, or the patient was awakened and a fiberoptic scope was used. In an attempt to determine a possible cause for their results, the authors noted a subset of type 1 diabetics suffering from diabetic stiff joint syndrome (SJS), also known as limited joint mobility (LJM) syndrome. This is a disease process by which microvascular disease leads to abnormal cross-linkage of collagen by non-enzymatic glycosylation in connective tissue as a result of chronic hyperglycemia. ${ }^{8}$ The au- thors theorized that the involvement of the atlanto-occipital joint in diabetic SJS might ultimately lead to difficult laryngoscopy. ${ }^{7}$

A more recent retrospective study by Warner et al. reviewed the same patient population and similarly found that type 1 diabetic patients were more prone to difficult laryngoscopy ( $4.8 \%$ vs $1.0 \%) .{ }^{9}$ They concluded that their results show, "patients with diabetes may have a modestly increased difficulty of laryngoscopy compared with those without diabetes, but they do not support the findings of greatly increased difficulty previously reported" and that "extraordinary techniques were not required to successfully manage their airways." "

\section{Do Type 2 Diabetics Have the Same Likelihood of Difficult Laryngoscopy as Type 1 Diabetics?}

The prevalence of type 2 diabetes continues to rise, and as stated earlier, is projected to double by the end of the next decade. ${ }^{1,2}$ It is seen more frequently in developed nations where populations have a greater likelihood to be overweight and battle obesity. ${ }^{10}$ Once largely thought of as a disease that only affected adults, it is now being seen more frequently in children and adolescents. ${ }^{6}$ The sequelae of the disease are far reaching, affecting nearly every organ system, and ultimately causing excess mortality. Anesthesiologists, serving as perioperative physicians, will care for patients with type 2 diabetes on a near daily basis. It is important to be well versed in not only the end organ complications of the disease, but also the airway issues that may be encountered in this patient population.

A 2003 prospective study from Erden et al. showed a statistically significant increase in difficult laryngoscopy ( $18.75 \%$ vs $2.5 \%)$ in type 2 diabetics vs non-diabetics. ${ }^{11}$ They defined difficult laryngoscopy as grade III and grade IV views based on Cormack-Lehane criteria. ${ }^{12}$ Vani et al. similarly found the incidence of difficult laryngoscopy (Cormack-Lehane grade III or IV view) in type 2 diabetics to be $16 \%{ }^{13}$

In addition to studying the incidence of difficult laryngoscopy in type 2 diabetics, the Erden and Vani et al. studies also attempted to establish a relationship between difficult laryngoscopy and the ability of patients to approximate the palmar surfaces of their phalangeal joints, previously described as the "prayer sign" or "palm print sign." The premise of the prayer sign or palm print sign is to grade the laxity of the phalangeal joints and establish a correlation between palmar joint rigidity and involvement of cervical and laryngeal tissues of diabetic patients that can lead to difficult laryngoscopy. As described earlier, diabetic patients are believed to have non-enzymatic glycosylation of collagen, which is subsequently deposited in the joints. This process can 
lead to diabetic SJS. Changes from this disease process can first be noted in the fourth and fifth interphalangeal joints and later in the atlanto-occipital joint. ${ }^{11}$ Diabetic SJS causes patients to have the inability to make a complete palmar approximation, despite maximal effort. Erden et al. were unable to show a relationship between the inability to complete the prayer sign and the likelihood of difficult laryngoscopy. ${ }^{11}$ Vani et al. found that the palm print sign had the highest sensitivity in ability to predict difficult laryngoscopy preoperatively compared to other commonly used predictors of difficult intubation. ${ }^{13} \mathrm{~A}$ recent study by Baig et al. demonstrated that the prayer sign had a lower sensitivity but similar specificity to Mallampati grade in predicting difficult laryngoscopy in the diabetic population. ${ }^{14}$

Though diabetes is frequently considered a predictor for difficult intubation, the incidence of difficult intubation in this patient population is likely less than originally thought and may actually be only slightly higher than the population at large. It must also be noted that the original studies were done at a time when traditional direct laryngoscopy or awake fiberoptic intubation were the methods used to manage an airway. Today, with the assistance of the devices such as the intubating supraglottic airway and video laryngoscopes, the rate of successful intubation in diabetic patients may actually be equivalent to that of the general population. To our best knowledge, this has not been formally studied.

The ability to predict difficult intubation by specific clinical exam findings continues to be debated in the literature. ${ }^{11,13-14}$ While the possibility of difficult intubation should always be considered in the diabetic population, other elements must be taken into consideration. A thorough preoperative evaluation should include a review of previous anesthetics and degree of difficulty of airway management, disease severity and control, as well as disease duration. Following the initial clinical history, a thorough airway evaluation, possibly including the prayer sign, is critical. If a difficult airway is suspected, appropriate preparations should be made including necessary rescue equipment and additional staff nearby. As with all cases, the ASA difficult airway algorithm must be used to guide management decisions.

Address for correspondence: Elizabeth Valentine, MD, Associate Director of Preoperative Medicine, Department of Anesthesiology and Critical Care, Perelman School of Medicine at the University of Pennsylvania, 3400 spruce street, Philadelphia, PA 19104

Email: Elizabeth.Valentine@uphs.upenn.edu

\section{Editor}

Jianzhong Sun, MD, PhD

Professor and Attending Anesthesiologist Department of Anesthesiology Jefferson Medical College Thomas Jefferson University and Hospitals 111 South 11th Street, Suite G8490Philadelphia, PA 19107

jian-zhong.sun@jefferson.edu

\section{Disclosure of Funding}

None

Additional publication details

Journal short name: Transl Perioper \& Pain Med

Received Date:November 1, 2014

Accepted Date: January 1, 2015
Published Date: January 3, 2015

Transl Perioper \& Pain Med 2015; 2(1):19-21

\section{Citation and Copyright}

Citation: Leonard Nowcid, Elizabeth Valentine. Difficult Airway in Diabetes. Transl Perioper \& Pain Med 2015; 2(1): 19-21

Copyright: () 2015 Leonard Nowcid, MD. This is an open-access article distributed under the terms of the Creative Commons Attribution License, which permits unrestricted use, distribution, and reproduction in any medium, provided the original author and source are credited. References

1. International Diabetes Federation. IDF Diabetes Atlas, 6th edn. Brussels, Belgium: International Diabetes Federation, 2013;9-10.

2. Wild S, Roglic G, Green A, Sicree R, King H. Global prevalence of diabetes: estimates for the year 2000 and projections for 2030. Diabetes Care. 2004;27(5):1047-53.

3. Apfelbaum JL, Hagberg CA, Caplan RA, Blitt CD, Connis RT, Nickinovich DG, Hagberg CA, Caplan RA, Benumof JL, Berry FA, Blitt CD, Bode RH, Cheney FW, Connis RT, Guidry OF, Nickinovich DG, Ovassapian A; American Society of Anesthesiologists Task Force on Management of the Difficult Airway. Practice guidelines for management of the difficult airway: an updated report by the American Society of Anesthesiologists Task Force on Management of the Difficult Airway. Anesthesiology. 2013;118(2):251-70.

4. Shiga T, Wajima Z, Inoue T, Sakamoto A. Predicting difficult intubation in apparently normal patients: a meta-analysis of bedside screening test performance. Anesthesiology. 2005;103(2):429-37.

5. Newacheck PW, Halfon N. Prevalence and impact of disabling chronic conditions in childhood. AMJ Public Health. 1998;88(4):610-17.

6. Bell RA, Mayer-Davis EJ, Beyer JW, D’Agostino RB Jr, Lawrence JM, Linder B, Liu LL, Marcovina SM, Rodriguez BL, Williams D, Dabelea D; SEARCH for Diabetes in Youth Study Group. Diabetes in non-Hispanic white youth: prevalence, incidence, and clinical characteristics: the SEARCH for Diabetes in Youth Study. Diabetes Care. 2009;32 Suppl 2:S102-11.

7. Hogan K, Rusy D, Springman SR. Difficult laryngoscopy and diabetes mellitus. Anesth Analg. 1988;67(12):1162-5.

8. Kim RP, Edelman SV, Kim DD. Musculoskeletal complications of diabetes mellitus. Clinical diabetes. 2001;19(3);132-135.

9. Warner ME, Contreras MG, Warner MA, Schroeder DR, Munn SR, Maxson PM. Diabetes mellitus and difficult laryngoscopy in renal and pancreatic transplant patients. Anesth Analg. 1998;86(3):516-9.

10. Nolan CJ, Damm P, Prentki M. Type 2 diabetes across generations: from pathophysiology to prevention and management. The Lancet. 2011;9;378(9786):169-81. 
11. Erden V, Bassaranoglu G, Delatiogu H, Hamzaoglu NS. Relationship of difficult laryngoscopy to long term non insulin dependent diabetes and hand abnormality detected using the 'prayer sign'. Br. J. Anaesth. 2003;91(1):159-160.

12. Cormack RS, Lehane J. Difficult tracheal intubation in obstetrics. Anaesthesia. 1984;39(11):1105-11.

13. Vani V, Kamath SK, Naik LD. The palm print as a sensitive predictor of difficult laryngoscopy in diabetics: a comparison with other airway evaluation indices. J Postgrad Med.

2000;46:75-9.

14. Baig MM, Khan FH. To compare the accuracy of prayer's sign and Mallampati test in predicting difficult intubation in diabetic patients. J Pak Med Assoc. 2014;64(8):879-83. 